The use of photographs as a form and possibility to make the register of the internal movements of the psychiatric citizens, was a common practice in the 19th Century, that have begun in France and England. The psychiatric photograph is closely related with the concept of exteriorization of the internal and spiritual movements on the body, something that is brought from de inside to the outside and that could be visually identified in the physiognomic and in the movements. Hugh Welch Diamond developed his photographic works in the Surrey Country Lunatic Asylum, in England. There, beyond the photographs themselves, Diamond discussed about the use of this resource and its advantages to the medicine. This study has as objectives: first of all to present the use of the psychiatric photograph as an integrant part of the medical behavior in relation to the patients in the 19th Century; secondly to point on the arguments of Hugh Diamond that detached the importance and the advantages of the use of this technique in medicine, using for that his own publication On the Application of Photography to the Physiognomic and Mental Phenomena of Insanity of 1856; and finally discuss some of the images made by him with engravings from the same thematic.

Keywords: Photography, psychiatry, Hugh Diamond. 


\title{
A fotografia psiquiátrica no século XIX: Hugh W Diamond ${ }^{1}$
}

\author{
Tatiana Fecchio da Cunha \\ GONÇALVES
}

O uso da fotografia como forma e possibilidade de registro das movimentações internas dos sujeitos psiquiátricos foi uma prática comum no século XIX, tendo se iniciado na França e Inglaterra. A fotografia psiquiátrica está intrinsecamente relacionada com a concepção de exteriorização das movimentações internas no corpo, da externalização de um estado patológico passível de ser percebido na fisionomia e na gestualidade. Hugh Welch Diamond desenvolveu seus trabalhos fotográficos no Surrey Country Lunatic Asylum, na Inglaterra. Lá, além da realização das fotografias, Diamond refletiu sobre o uso deste recurso e suas vantagens junto à medicina. Este estudo tem por objetivos: primeiramente apresentar o uso da fotografia psiquiátrica como parte integrante da conduta médica em relação aos pacientes no século XIX; em segundo lugar apontar sobre os argumentos de Hugh Diamond que destacavam a importância e as vantagens da utilização desta técnica a partir de seu próprio relato na publicação On the Application of Photography to the Physionomic and Mental Phenomena of Insanity de 1856; bem como discutir particularidades das imagens por ele realizadas em relação às gravuras de mesma temática.

Palavras-chave: Fotografia, psiquiatria, Hugh Dia- 
As primeiras imagens fotográficas referentes ao louco e à loucura datam da segunda metade do século dezenove. Na sua origem os registros fotográficos abordando o louco e a loucura voltaram-se para a construção de tipologias de doenças, numa referência classificatória, vinculando-se à tradição da pintura, inaugurada por Leon Battista Alberti (1404-1472), voltada para a expressão dos movimentos da alma através dos movimentos dos corpos e da fisionomia. As fotografias do século dezenove possuíam inicialmente função diagnóstica e deram suporte a estudos que associavam a forma fisionômica às características condicionantes de determinada patologia, se aproximando dos estudos criminais da mesma época.

O desenvolvimento da fotografia psiquiátrica no século XIX foi, em todo o caso, criada a partir da mesma motivação que aquela da fotografia judicial

...entre Salpêtrière e a Delegacia de policia: as técnicas fotográficas eram as mesmas, e tinham as mesmas esperanças/objetivos (....as primeiras fotografias de identidade eram tão trabalhadas quanto os retratos de família e, principalmente, me parece que depende de uma arte, em algum momento, toda paixão pelas formas e configurações). Como Salpêtrière e a delegacia de polícia foram ajudadas em seus esforços pela Escola de Belas Artes, é isso que será necessário questionar. O desenvolvimento da fotografia psiquiátrica no século XIX é em todo caso constituído ao mesmo tempo que a fotografia judicial, uma disciplina de articulação; ocupa ai alias uma eminente posição estratégica, que foi a antropologia criminal: ela se interessa aos retratos fotográficos dos criminosos e dos alienados tanto quanto à seus crânios. ${ }^{2}$

Havia a proposição de que a fisionomia seria reveladora de tipos específicos de caráter, associados a determinados perfis de doença ou a perfis criminais. Assim, a representação fotográfica passou a ser utilizada não como a reveladora de individualidades, mas como instrumento cientfico propiciador ao estabelecimento de identificações necessárias à classificação de um determinado indivíduo junto a categorias ou tipologias pré-determinadas.

A utilização da fotografia como recurso científico nos estudos da fisionomia, da eugenia e nesta época também da psi- 
quiatria, vai se construindo através da boa adequação que a técnica apresenta em relação às diversas demandas desta função.

A coleta de informações sobre as raças e fisionomias passa a ser desejada ao aprofundamento e comprovações de tais teorias.

Sem surpresa, no intuito de agregar imagens e informações em uma escala massiva e através de todo o mundo, a nova arte da fotografia foi posta em serviço, particularmente na Inglaterra, onde a ascensão do império facilitou planos privados e oficiais para a documentação de toda a sorte de tipos faciais e corporais.

O impasse que se colocava, então, era a forma de coleta destas informações ao redor do mundo. A pintura e a gravura poderiam ser utilizadas, mas implicavam explicitamente na leitura e recursos técnicos disponíveis ao artista. É neste contexto que a fotografia se mostra uma técnica de coleta de dados ideal, pois a princípio minimizaria a interferência do autor/fotógrafo. Ela se apresentava como uma ferramenta adequada à captao mais realista das imagens fisionômicas e de tipos e uma vez que derivada de um aparato técnico e mecânico, a princípio, e para a compreensão da época, poderia ser empregada independentemente dos sujeitos fotografados e tampouco do fotógrafo, eliminando assim o indesejado caráter subjetivo, pois não científico, potencialmente decorrente de seus autores.

A fotografia apresentava três grandes vantagens em relação à gravura e à pintura: as imagens poderiam ser produzidas mais rapidamente do que as pinturas/desenhos/gravuras, poderiam ser reproduzidas em maior número e este fato propiciaria uma propagação mais efetiva deste conhecimento uma vez que estudiosos de locais distantes poderiam se deparar exatamente com a mesma imagem. Neste período se constituirá o colecionismo de fotografias de grupos étnicos, criando os museus de tipos. ${ }^{4}$

Se o uso da fotografia se deu no campo do registro e estudo das diferenças étnicas, rapidamente migrou a outros campos da ciência, passando a ser utilizada ao registro e classificação de tipos nos asilos psiquiátricos da época. No caso dos loucos a representação dos tipos também se fazia anteriormen- 
te por pintores ${ }^{5}$, no entanto corria-se o risco de incorrer em uma excessiva humanidade não científica: O problema de usar um artista com a pertinncia de Gricault que o que ns instintivamente sentimos como sendo a mais profunda traduo da natureza humana faz a extrao esquemtica de sinais gerais mais, ao invs de menos, difcil ${ }^{6}$. Ou seja, na ação do artista, por mais pertinente e realista que fosse, era entendida a existência de uma transformação do assunto representado, mesmo que esta ao final revelasse o mais humano daquele retratado. Este fato era compreendido como dificultador da análise efetivamente direta, menos camuflada ou intermediada, em relação aos sinais do objeto em si, sendo que esta mediação não era desejada, pois despotencializava a assertividade científica da observação direta, confundindo/desviando o olhar científico dos sinais reais e com isto decorrendo em classificações menos precisas pois apoiadas na subjetividade do artista.

Assim, a no subjetividade fotográfica seria entendida como de grande valia a estes registros e estudos, aparecendo como uma ferramenta adequada para a categorização visual do insano, cabendo a ela a ...leitura de sinais da face e do corpo ${ }^{7}$.

O uso da fotografia em Hospitais Psiquiátricos decorrerá de mudanças que ocorrem nestes ambientes de internação, bem como da proximidade e interesse dos médicos aos estudos fotográficos. Estes trabalhos terão início predominantemente em dois grandes centros médicos do século XIX. Na França, no Hospital Salpetriere, no qual trabalharam Philippe Pinel (1745-1826), Jean Dominique Esquirol (1772-1840), Duchene de Boulogne (1806-1875), Jean Martin Charcot (1825-1893), Désiré-Magloire Bourneville (1840 - 1909) (que depois vai trabalhar em Bicètre), Paulo Regnard, Albert Londe (1858-1917), Paul Richer (1849-1933) e na Inglaterra, no Hospital Surrey Country Lunatic Asylum, onde trabalharam Morison Alexander (1813 - 1887), Hugh Welch Diamond (1809-1886) (que antes tem sua formação no Hospital de Bethlen e depois trabalha no Asilo particular Twickenhan House), no Hospital de Bethlen onde trabalharam Sir Georges Tuthill (1722-1835), e no Asilo de Hanwell onde trabalhou John Conolly (1794-1866).

As síndromes de insanidade seriam estudadas através de 
seus efeitos sobre os corpos, seriam compreendidas através de alterações comportamentais e sinais físicos, sendo que dentre as partes do corpo, aquela na qual melhor poderiam ser captados os sinais da patologia, na qual se concentraria de forma mais evidente a doença em termos da visualidade, estava a face humana.

O importante é que, neste momento, a loucura passa a poder ser identificada externamente aos $\operatorname{corpos}^{8}$ e portanto se torna passível de registro. De fato, para a psiquiatria da metade do início do século dezenove, tendo por base as formulações de Lavater e da frenologia, era possível entender que ...a natureza da insanidade poderia ser lida em detalhes precisos derivados das caractersticas das pessoas afligidas, e ainda mais precisamente, que a insanidade resultava de defeitos fsicos ${ }^{9}$. Assim, tanto os defeitos e as características das movimentações externas no corpo, quanto os movimentos internos refletidos externamente, poderiam ser capturados e registrados na imagem fotográfica.

O pioneiro no uso da fotografia no campo da saúde mental na Inglaterra foi o Dr. Hugh Diamond. Como membro fundador da Royal Photographic Society, Diamond possuía as ferramentas técnicas para construir imagens que não apenas

....apreendiam a atenção do observador mas também transcendiam as limitações da descrição verbal, desde que, como ele dizia 'cada figura fala por si mesma com cada uma das marcas impressas e indica o ponto exato em que foi atingida na escala de infelicidade ${ }^{10}$.

Instalado à maneira de um estúdio fotográfico, o trabalho de Diamond tinha por objetivo capturar da população em estudo ...os aspectos da expresso e maneiras que se configuravam fora das normas sociais, ambos na vida real e mais particularmente em sintonia com as convenes dos retratos fotogrficos da classe mdia $^{12}$.

Na década de 30 Conolly, professor de medicina na Universidade de Londres, havia publicado estudos onde trazia ao contexto britânico, as inovações e reformas de Pinel na França, conceitos que influenciariam a psiquiatria em diversos centros 
europeus. Em 1948 Diamond se torna o superintendente da Seção feminina do Surrey Country Lunatic Asylum em Twickenham onde trabalhou até 1858. Diamond se interessa pelos processos fotográficos, tem contato com os trabalhos de W. $\mathrm{H}$. Fox Talbot que desenvolve o processo da calotipia. Publica inúmeros ensaios sobre fotografia no Notes and Queries, dentre estes um artigo apresentado na Phtographic Society em 1953 intitulado The Simplicity of the Calotype Porcess.

O trabalho de Diamond realizado no Springfield Asylum (Surrey) gerou uma exposição em Londres intitulada Types of Madness, baseado em uma série de fotografias ali realizadas. Este estudo

...foi o primeiro uso sistemático da fotografia na história da psiquiatria pautado na tradição fisionômica de J. E. D. Esquirol, o qual teve mais de duzentos pacientes fotografados em Salpêtrière, e Sir Alexandres Morison (predecessor de Diamond no Surrey Asylum), de quem surge o importante Atlas of the Physiognomy of Mental Diseases em 1838, Diamond cuida de registrar a aparência do insano para uso clínico.

As fotografias então veiculadas deram origem a litogravuras de John Conolly e que foram publicadas no Case Studies from The Physiognomy of Insanity ${ }^{14}$, de 1858.

Esta publicação apresenta para cada dupla de imagens (uma fotografia e uma litogravura realizada a partir da fotografia) um texto contextualizando a situação clínica do paciente retratado. Sobre esta publicação Gilman comenta ...a importncia da fotografia como oposta a outras formas de ilustrao pode ser notada, mesmo contemporneos notaram a acentuada diferena entre a fotografia original e as litogravuras nelas baseadas $^{15}$ e num outro trecho complementa que mais ... evidente a ausncia de detalhes finos na alterao e reinterpretao da aparncia do paciente, a gravura da fotografia altera o valor da ilustrao mas no a destri.

Para Conolly suas gravuras davam continuidade aos trabaIhos de Esquirol e Morison, substancialmente seguindo a tradição de Lavater do século XVIII; porém considerava que estes ganhavam maior valor empírico por terem sido realizadas a par- 
tir de fotografias, revelando sua crença de que a fotografia se configurava como retrato objetivo da doença.

Em 22 de Maio de 1956, Diamond apresenta suas pesquisas à Royal Society britânica num artigo intitulado On the application of Photography in the physionomic and mental Phenomena of Insanity ${ }^{17}$. Este estudo foi ...o primeiro esforo para apresentar uma discusso sistemtica de representao do insano neste novo meio ${ }^{18}$, ou seja, a pesquisa da loucura com a utilização da fotografia. Neste artigo Diamod argumenta sobre as vantagens da utilização da técnica fotográfica, justificadas agora não apenas ao registro de tipos mas particularmente à imagem do paciente psiquiátrico. Neste sentido a fotografia possuiria ao menos três importantes funções no tratamento do mentalmente doente

Ela poderia fixar/preservar a aparência do doente mental para estudo (endossando as teorias da fisionomia da insanidade aceitas neste período); ela poderia ser usada no tratamento do mentalmente doente através da apresentação de uma imagem própria acurada; e ela poderia fixar/preservar a aparência de pacientes para facilitar sua identificação em readmissão posterior e tratamento .

Este trabalho de Diamond foi um marco no desenvolvimento da ilustração/representação psiquiátrica, ... co compreenso do papel do retrato do insano e a aceitao do retrato como prova emprica da sintomatologia psiquitrica, Diamond postulou uma nova e grande tradio da fisionomia da insanidade ${ }^{20}$.

De fato, até então, a forma de compreender e produzir este tipo de representação era de outra ordem, como em Charles Lê Brun que em 1806 dizia ser a representação da doença de cunho moralizador, de exemplificar com determinada imagem as conseqüências de vício e indulgência seguindo a tradição do século XVIII como a existente no The Rakes Progress de Hogar$t h^{21}$. O trabalho de Diamond, no entanto, se aproximará mais às pesquisas de Esquirol $^{22}$ que já argumentará sobre a representação, de forma mais engajada com as discussões da escola de Pinel, como um estudo que poderia acrescer ao médico no revelar sobre o caráter das idéias e emoções durante a fase de delírio dos sujeitos. Ainda mais, com Diamond a postura frente 
à imagem fotográfica fica acrescida de uma possibilidade de interpretação de uma sintomatologia.

As fotografias de Diamond foram também influenciadas por fotógrafos da época como Julia Margatet Cameron e Lewis Carroll. Suas fotografias tinham uma estrutura compositiva semelhante aos retratos, não científicos, realizados neste período. Havia uma preocupação estética que os diferenciava dos trabalhos de Atlas construídos, até então, a partir desta população. Os trabalhos de Diamond ...fornecem uma estrutura esttica. Pois, enquanto a temtica para o interesse mdico, as fotografias elas mesmas possuem uma importncia esttica atravs da manipulao cuidadosa do formato a fim de obter o maior efeito no observador ${ }^{23}$.

Em 1858 Diamond deixa o Hospital em Surrey e abre uma Asilo privado em Twickenhan House em Middlesex por ele próprio dirigido até sua morte em 1886. Com Diamond a fotografia passou a ser empregada e utilizada em diferentes Asilos.

Com estas discussões pretendeu-se apontar sobre como se deu o emprego da fotografia junto à medicina, as vantagens científicas identificadas nesta ferramenta de registro e ilustração em função de suas características mecânicas e reprodutíveis que se adequavam às demandas de uma ciência e de um tempo que viu nesta forma de coletar imagens a praticamente ausência de subjetividade, indesejada pois não científica, derivada de seus autores. Pretendeu-se também evidenciar de forma mais específica o uso da fotografia dentro do campo da psiquiatria e apontar as características que foram valorizadas nos estudos de Diamond, estudos estes que praticamente repostularam a forma de registro no campo da psiquiatria. Se estas imagens estavam vinculadas as ilustrações dos Atlas que se realizava até então, vinculadas à linguagem de época dos retratos; a estes também acrescia novos elementos, possibilidades, propagação e principalmente credibilidade cientifica. 


\section{Notas}

1. GT História, teoria e crítica da arte e da imagem.

2. DIDI-HUBERMAN, 1982:59 (agradeço aqui a colaboração de Cris Motta Boulnois na tradução do original em Francês).

3. KEMP,2001:121.

4. A coleção de Carl Dammann é importante neste sentido na Inglaterra, gerando posteriomrnte uma Galeria Dammann's Gallery e publicações como The Ethnographic Gallery of the races of Men.

5. Um vasto número de obras pode ser incluído neste grupo, entre elas as gravuras de Hogarth, Theodore Géricault e Andrew Scull. Entre as pinturas aqui se localizam trabaIhos de Gericault, Goya, Eugene Delacroix e Antoine Wiertz.

6. KEMP, 2001:130.

7. KEMP, 2001:132.

8. Esta é uma questão importante pois a loucura, sendo um transtorno psíquico não tem, a princípio, sinais externos como em outras patologias ou deficiências físicas. A possibilidade de registrar e aferir cientificamente no corpo a doença significava, de fato, uma nova e importante possibilidade à medicina da época.

9. KEMP,2001:125.

10. KEMP,2001:130.

11. Diamond não realizará sua formação junto à Conolly no Asilo de Hanwell, mas junto à Tuthill no Hospital de Bethlem.

12.KEMP,2001:130.

13. GILMAN, 1976:07.

14. Este artigo publicado originalmente em The Medical Times and Gazette (1858) com pranchas de imagesn de 1-17 está compilado no livrro de Gilman The Face of Madness: Hagh W. Diamond and the Origin of Psychiatric Photography de 1976.

15. GILMAN, 1976:11.

16. GILMAN, 1976:11.

17. Este artigo está compilado no livrro de Gilman The Face of Madness: Hagh W. Diamond and the Origin of Psychiatric Photography de 1976.

18. GILMAN, 1996:164.

19. GILMAN, 1976:07/08.

20. GILMAN, 1976:08.

21. The Rake's Progress, de William Hogarth, ilustra em oito imagens (sendo um conjunto de pinturas e outro de gravuras) o declínio e queda de Tom Rakewell, um jovem abastado filho de um rico comerciante que chega a Londres, gasta todo o seu dinheiro em luxuria, prostituição e vadiagem sendo ao final preso e por fim indo parar no Hospital de Bethlen. As imagens foram produzidas entre 1732 e 1733 e puvblicadas em 1735.

22. As imagens de Diamond se identificam aos trabalhos de Esquirol, publicados no Dictionnaire dês sciences médicales ou nas gravuras presentes em suas publicações de 1938.

23. GILMAN, 1976:09. 


\section{Referências}

ALBERTI, Leon Battista, Da Pintura, tradução de Antonio da Silveira Mendonça, Campinas; editora da Unicamp; 1989 (Coleção Repertório), p.114 BINDMAN, David. Hogarth. Thames and Hudson: Syngapore, 1981.

BINDMAN, David. Ape to Apollo: Aesthetics and the Idea of race in the 18th Century. Reaktion Books Ltd, London, 1940.

DIAMOND, Hugh W. The Face of Madness: Hugh W. Diamond and the origin of psychiatric photography. Brunner/Mazel: New York, 1976.

DIAMOND, Hugh W. On the Application of Photography to the Physiognimic and Mental Phenomena of Insanity (lido ante a Royal Society em 22 de maio de 1856) em GILMAN, Sander L. The Face of Madness: Hugh Diamond and the Origin of the Psychiatric Photograph. Brunner/Mazel Publishers, New yourk, p.19-24, 1977.

DIAMOND, Hugh W. On The Simplicity of the Catotype Process em Notes and Queries vol. 8 (17 Dec), p.597, 1953.

DIDI-HUBBERMAN, Georges, Invencin de LHiysterie: Charcot et Liconographie Photographique da la Salptrire, Macula, Paris, 1982

GILMAN, Sander L. Disease and Representation: Images of IIIness from Madness to Aids. Cornell University Press, Ithaca and London, 1988.

GILMAN, Sander L. The Face of Madness: Hugh Diamond and the Origin of the Psychiatric Photograph. Brunner/Mazel Publishers, New yourk, 1977.

GILMAN, Sander. Seeing the Insane. University of Nebraska Press, New York, 1982.

GILMAN, Sander. Difference and Pathology: Stereotypes of Sexuality, Race and Madness. Cornell University Press, Ithaca and London, 1985.

MORISON, Alexander. The Physiognomy of Mental Diseases (1958) em Classics in Psychiatry, advisory editor Eric T. Carlson. New York: Arno Press, New York Times Company, 1976.

PINEL, Philippe. Trait mdico-philosophique sur lalination mentale, ou la manie. Paris: Chez Richard, Caille et Ravier, Libraires, 1801.

PINEL, Philippe. A Treatise on Insanity. Translated by David Daniel Davis. Birmingham Alabama: The Classics of Medicine Library, 1983.

PINEL, Philippe. Nosographie Philosophique ou Mthode de lanalyse applique la mdecine, 1798.

WHITE, Charles. An Account of the Regular Gradation in Man, and in different Animals and Vegetables; and from the former to the latter, C. Dilly, London, 1799. 


\section{TATIANA FECCHIO DA CUNHA GONÇALVES}

Doutoranda em Artes na Universidade Estadual de Campinas/ Unicamp realizando estágio sanduíche em Londres Wellcome Trust Centre for the History of Medicine/ UCL financiamento FAPESP/CAPES, Mestre em Artes/ Unicamp (2004), bacharel e licenciada em Educação Artística/ Unicamp (2001). Especialista em Arteterapia/ Unicamp (2003) e especialista em Artes e Novas Tecnologias na Universidade de Brasília/ UnB (2005). Membro dos grupos de Pesquisa: Transferência Cultural entre Europa e América Latina (IA/ Unicamp) e Desenvolvimento, Linguagem e Práticas 